\title{
Dual-Modality Imaging of Prostate Cancer with a Fluorescent and Radiogallium-Labeled Gastrin-Releasing Peptide Receptor Antagonist
}

\author{
Hanwen Zhang ${ }^{1}$, Pooja Desai ${ }^{1}$, Yusuke Koike ${ }^{1,2}$, Jacob Houghton ${ }^{1}$, Sean Carlin ${ }^{1}$, Nidhi Tandon ${ }^{1}$, Karim Touijer ${ }^{2}$, \\ and Wolfgang A. Weber ${ }^{1,3}$ \\ ${ }^{1}$ Department of Radiology, Memorial Sloan Kettering Cancer Center, New York, New York; ${ }^{2}$ Department of Surgery, Memorial Sloan \\ Kettering Cancer Center, New York, New York; and ${ }^{3}$ Molecular Pharmacology and Chemistry Program, Memorial Sloan Kettering \\ Cancer Center, New York, New York
}

Gastrin-releasing peptide (GRP) receptors (GRPr) are frequently overexpressed in human prostate cancer, and radiolabeled GRPr affinity ligands have shown promise for in vivo imaging of prostate cancer with PET. The goal of this study was to develop a dualmodality imaging probe that can be used for noninvasive PET imaging and optical imaging of prostate cancer. Methods: We designed and synthesized an IRDye 650 and DOTA-conjugated GRPr antagonist, HZ220 (DOTA-Lys(IRDye 650)-PEG ${ }_{4}$-[D-Phe ${ }^{6}$, $\left.\left.\mathrm{Sta}^{13}\right]-\mathrm{BN}(6-14) \mathrm{NH}_{2}\right)$, by reacting DOTA-Lys-PEG ${ }_{4}$ [D-Phe $\left.{ }^{6}, \mathrm{Sta}^{13}\right]-$ $\mathrm{BN}(6-14) \mathrm{NH}_{2}(\mathrm{HZ219})$ with IRDye $650 \mathrm{~N}$-hydroxysuccinimide (NHS) ester. Receptor-specific binding of gallium-labeled HZ220 was characterized in PC-3 prostate cancer cells (PC-3), and tumor uptake in mice was imaged with PET/CT and fluorescence imaging. Receptor binding affinity, in vivo tumor uptake, and biodistribution were compared with the GRPr antagonists HZ219, DOTA-PEG ${ }_{4}$ [D-Phe ${ }^{6}$, $\mathrm{Sta}^{13}$-BN(6-14) $\mathrm{NH}_{2}$ (DOTA-AR), and DOTA-(4-amino-1-carboxymethylpiperidine)-[D-Phe $\left.{ }^{6}, \mathrm{Sta}^{13}\right]-\mathrm{BN}(6-14) \mathrm{NH}_{2}$ (DOTA-RM2). Results: After hydrophilic-lipophilic balance cartridge purification, ${ }^{68} \mathrm{Ga}-\mathrm{HZ} 220$ was obtained with a radiochemical yield of $56 \% \pm 8 \%$ (non-decaycorrected), and the radiochemical purity was greater than $95 \%$. $\mathrm{Ga}-\mathrm{HZ} 220$ had a lower affinity for GRPr (inhibitory concentration of $50 \%$ [IC $\left.\left.{ }_{50}\right], 21.4 \pm 7.4 \mathrm{nM}\right)$ than Ga-DOTA-AR ( $\left.\mathrm{IC}_{50}, 0.48 \pm 0.18 \mathrm{nM}\right)$ or Ga-HZ219 $\left(\mathrm{IC}_{50}, 0.69 \pm 0.18 \mathrm{nM}\right)$. Nevertheless, ${ }^{68} \mathrm{Ga}-\mathrm{HZ} 220$ had an in vivo tumor accumulation similar to ${ }^{68} \mathrm{Ga}-\mathrm{DOTA}-\mathrm{AR}(4.63 \pm 0.31$ vs. $4.07 \pm 0.29$ percentage injected activity per $\mathrm{mL}[\% \mathrm{IA} / \mathrm{mL}]$ at $1 \mathrm{~h}$ after injection) but lower than that of ${ }^{68} \mathrm{Ga}-\mathrm{DOTA}-\mathrm{RM} 2(10.4 \pm$ $0.4 \% \mathrm{IA} / \mathrm{mL}$ ). The tumor uptake of ${ }^{68} \mathrm{Ga}-\mathrm{HZ} 220$ was blocked significantly with an excessive amount of GRP antagonists. IVIS spectrum imaging also visualized PC-3 xenografts in vivo and ex vivo with a high-contrast ratio. Autoradiography and fluorescent-based microscopic imaging with ${ }^{68} \mathrm{Ga}-\mathrm{HZ} 220$ consistently colocated the expression of GRPr. ${ }^{68} \mathrm{Ga}-\mathrm{HZ} 220$ displayed a higher kidney uptake than both ${ }^{68} \mathrm{Ga}-\mathrm{DOTA}-\mathrm{AR}$ and ${ }^{68} \mathrm{Ga}-\mathrm{DOTA}-\mathrm{RM} 2(16.9 \pm 6.5$ vs. $4.48 \pm$ 1.63 vs. $5.01 \pm 2.29 \% \mathrm{IA} / \mathrm{mL})$. Conclusion: ${ }^{68} \mathrm{Ga}-\mathrm{HZ} 220$ is a promising bimodal ligand for noninvasive PET imaging and intraoperative optical imaging of GRPr-expressing malignancies. Bimodal nuclear/ fluorescence imaging may not only improve cancer detection and guide surgical resections, but also improve our understanding of the uptake of GRPr ligands on the cellular level.

Received Mar. 23, 2016; revision accepted Jul. 12, 2016.

For correspondence or reprints contact: Wolfgang A. Weber, Departments of Radiology, Molecular Pharmacology and Chemistry Program, SKI, Memorial Sloan Kettering Cancer Center, 1275 York Ave., New York, NY 10065.

E-mail: weberw@mskcc.org

Published online Aug. 11, 2016.

COPYRIGHT (C) 2017 by the Society of Nuclear Medicine and Molecular Imaging.
Key Words: GRP receptor; bombesin antagonist; optical imaging; PET imaging; prostate cancer

J Nucl Med 2017; 58:29-35

DOI: 10.2967/jnumed.116.176099

\section{$\mathbf{T}$} he goals of surgery in prostate cancer are to completely resect the primary tumor and metastatic lymph nodes as well as fully recover continence and potency. However, these 2 goals are inextricably linked, with the result that improvements in one outcome may occur at the expense of others. Prostate cancer has been traditionally among the most difficult malignancies to image because of its multifocal nature, and it is even more challenging for surgeons to identify the malignant lesions intraoperatively. Thus, surgeons have to risk injury to nerves, sphincter, or bladder to increase the chances of achieving a complete resection. Conversely, small islands of cancer may be missed, leading to positive surgical margins (11\%-41\% of surgical cases) (1), resulting in 2to 4 -fold-higher cancer recurrence rates per year in these patients $(1,2)$. Less invasive surgical approaches would be more feasible if prostate cancer could be localized more accurately. An attractive strategy to achieve localization of prostate cancer is dual-modality imaging probes that are labeled with a fluorescent dye and a positron emission radioisotope. The radioisotope is used for preoperative PET imaging and surgical planning, for example, to determine which lymph node regions should be dissected. During surgery, the fluorescent dye is used for intraoperative guidance using real-time fluorescence imaging (3-5).

An attractive target for imaging of prostate cancer is the gastrinreleasing peptide (GRP) receptor (GRPr) bombesin receptor subtype 2 (6). An autoradiographic study of human prostate cancers found receptor-specific binding of radiolabeled bombesin in all studied tumors $(n=30)$ and also in prostatic intraepithelial neoplasia. In contrast, normal prostate and benign prostate hyperplasia demonstrated only minimal binding of bombesin (7). On the basis of these data, several radiolabeled bombesin analogs have been developed (8-10). Recently, the GRPr antagonist ${ }^{68}$ Ga-DOTA-RM2 (BAY 86-7548) has shown significant potential for imaging of primary prostate cancer and lymph node metastases (11).

Among several strategies that have been used to design dualmodality probes for in vivo targeting (12-14), we proposed to use 
2 amines of lysine for conjugating radionuclide-chelated complexation and near-infrared fluorescent (NIRF) dye, respectively. For this study, we designed and synthesized a new ${ }^{68} \mathrm{Ga}$ and fluorescentconjugated GRPr antagonist $\left({ }^{68} \mathrm{Ga}-\mathrm{HZ} 220\right)$ based on the affinity sequence of ${ }^{68} \mathrm{Ga}$-DOTA-RM2 (Fig. 1) (15). We then investigated whether the dual-modality imaging probe retained its affinity for GRPr and studied its biodistribution in tumor-bearing mice. Finally, we investigated the feasibility of fluorescence imaging of GRPrexpressing tumors with ${ }^{68} \mathrm{Ga}-\mathrm{HZ} 220$.

\section{MATERIALS AND METHODS}

\section{Precursor Synthesis}

The source of chemicals and other materials is summarized in the supplemental methods section (supplemental materials are available at http://jnm.snmjournals.org). For peptide synthesis, amino acids were loaded to Rink amide MHBA resin using a standard Fmoc strategy. The bifunctional DOTA-tris(tBu)-ester was coupled to the $\mathrm{N}$ terminus of the peptide on resin by following a published protocol (16). After the peptide resin was treated with washing solvents and dried under vacuum at room temperature, the peptides were cleaved from the resin with trifluoroacetic acid/thioanisole $/ \mathrm{H}_{2} \mathrm{O}$ cocktail and purified with a high-performance liquid chromatography system (column: Phenomenex Luna C18(2), $250 \mathrm{mm \AA ̊} 20.0 \mathrm{~mm}, 5 \mathrm{~mm}, 100 \AA$ ஷ ultraviolet detector: $280 \mathrm{~nm}$; flow rate: $15 \mathrm{~mL} / \mathrm{min}$; mobile phase: $0.1 \%$ trifluoroacetic acid in water and $\mathrm{MeCN}$; gradient: $0-1 \mathrm{~min}, 2 \%-10 \% \mathrm{MeCN}, 1-16 \mathrm{~min}$, $10 \%-50 \% \mathrm{MeCN}, 16-18.5 \mathrm{~min}, 50 \%-100 \% \mathrm{MeCN}, 24.5 \mathrm{~min}, 100 \%$ $\mathrm{MeCN}, 25 \mathrm{~min}, 2 \% \mathrm{MeCN})$. To couple the fluorescent dye IRDye 650 to the peptide HZ219 (Fig. 1), the purified HZ219 and IRDye $650 \mathrm{~N}$-hydroxysuccinimide (NHS) ester $\left(\right.$ ratio $=1 / 1$ ) in $\mathrm{H}_{2} \mathrm{O}$ were mixed, and the $\mathrm{pH}$ value of the reaction solution was adjusted to 9 with a traceable amount of $\mathrm{N}, \mathrm{N}$-diisopropylethylamine. The reaction solution was incubated for $1 \mathrm{~h}$ at room temperature and purified to generate pure HZ220. All synthesized ligands were characterized with ultra-performance liquid chromatography-mass spectrum (UPLC-MS) (column: Waters Acquity BEH C18, $1.7 \mathrm{~mm}, 2.1 \times$ $100 \mathrm{~mm}, 130 \AA$ A flow rate: $0.3 \mathrm{~mL} / \mathrm{min}$; mobile phase: $0.05 \%$ trifluoroacetic acid in water and $\mathrm{MeCN}$; gradient: 0-5.0 min, 30\%45\% MeCN; 5.5-6.5 min, 95\% MeCN; 6.5-8 min, 30\% MeCN).

\section{Preparation of ${ }^{68} \mathrm{Ga},{ }^{67} \mathrm{Ga}$, and ${ }^{\text {nat }} \mathrm{Ga}$-Chelated Peptide}

All ${ }^{67} \mathrm{Ga}$-labeled conjugates were prepared by dissolving $5-10 \mathrm{nmol}$ peptide in $80 \mu \mathrm{L}$ of $0.5 \mathrm{M}$ ammonium-acetate buffer ( $\mathrm{pH}$ 5.4) and adding 37-74 MBq of ${ }^{67} \mathrm{GaCl}_{3}$ solution (10-20 $\mu \mathrm{L}$ ) followed by a

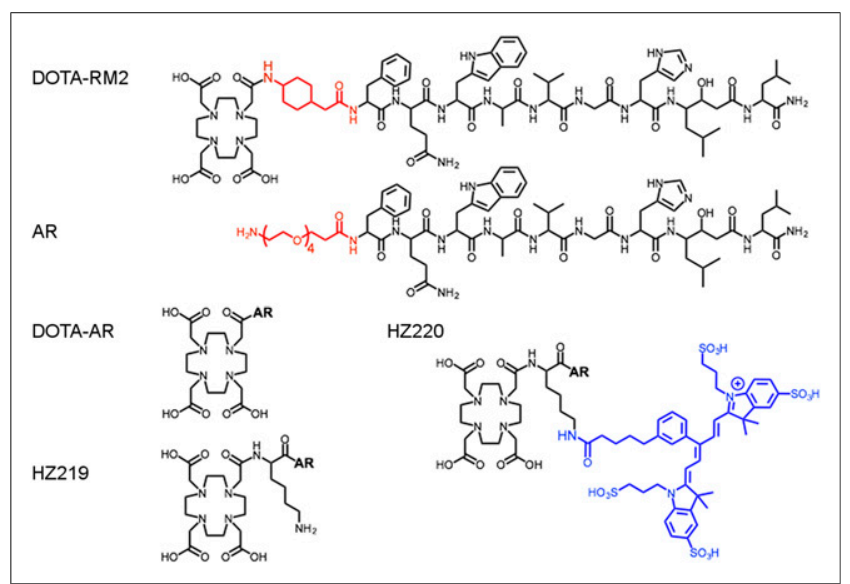

FIGURE 1. Schematic structure of studied GRPr ligands. 15-min incubation at $95^{\circ} \mathrm{C}$. Then, 3 equivalents of ${ }^{\text {nat }} \mathrm{Ga}\left(\mathrm{NO}_{3}\right)_{3} \cdot 5 \mathrm{H}_{2} \mathrm{O}$ were added, and the final solution was incubated for another $15 \mathrm{~min}$ to generate structurally identical Ga-labeled ligands. For ${ }^{68} \mathrm{Ga}$ labeling, $\left[{ }^{68} \mathrm{Ga}\right] \mathrm{Ga}(\mathrm{OH})_{4}{ }^{-}(111-740 \mathrm{MBq}$ in $0.5 \mathrm{~mL} \mathrm{KOH})$ was obtained from the generator, and the $\mathrm{pH}$ value was then adjusted to 4 with acetic acid for the labeling with DOTA-RM2 and DOTA-AR and to 5 for HZ220. After incubation and purification with a hydrophilic-lipophilic balance cartridge (Waters Corp.), the final product was reformulated with a phosphate-buffered saline/bovine serum albumin (1.0\% bovine serum albumin) solution and analyzed with analytic high-performance liquid chromatography (column: Luna C8(2), $100 \AA$ A, $2 \times 100 \mathrm{~mm}$; flow rate: $0.6 \mathrm{~mL} / \mathrm{min}$; mobile phase: $0.1 \%$ trifluoroacetic acid in water and MeCN; gradient: 0-10 min, 10\%-50\% MeCN; 11-14 min, 95\% MeCN; $15 \mathrm{~min}, 10 \% \mathrm{MeCN})$. ${ }^{\text {nat }} \mathrm{Ga}$-labeled peptides were synthesized with a similar procedure, and the final product in $\mathrm{H}_{2} \mathrm{O}$ was lyophilized and characterized with UPLC-MS.

\section{Binding Affinity Assays}

To determine the affinity of the synthesized peptides for GRPr, competitive binding studies were performed with PC-3 cells using [ [ ${ }^{125} \mathrm{I}-$ $\mathrm{Tyr}^{4}$ ] BN (GRPr ligand) and increasing concentrations of nat $\mathrm{Ga}$-chelated DOTA-RM2, DOTA-AR, HZ219, and HZ220 (17). Briefly, triplicate samples containing $0.5 \times 10^{6}$ cells, $1.85 \mathrm{kBq}$ of $\left[{ }^{125} \mathrm{I}_{-\mathrm{Tyr}}{ }^{4}\right] \mathrm{BN}$, and $0.001-1,000 \mathrm{nM}$ of the tested ligands (total volume, $0.5 \mathrm{~mL}$ ) were incubated at $37^{\circ} \mathrm{C}$ for $2 \mathrm{~h}$. After incubation, the cells were isolated by rapid filtration through glass microfiber filters (cat. no. FP-100; Brandel) and washed with $3 \times 3 \mathrm{~mL}$ of ice-cold tris-buffered saline ( $\mathrm{pH}$ 7.4). The radioactivity in the cells was measured with a $\gamma$-counter. The inhibitory concentration of $50 \%\left(\mathrm{IC}_{50}\right)$ values were estimated using a least-squares fitting routine (GraphPad Prism 6; GraphPad Software).

\section{In Vitro Cell Uptake and Fluorescence Microscopy}

To study the kinetics of cellular uptake of HZ220 (16), $0.5 \times 10^{6}$ PC-3 cells were seeded into 6-well plates, and on the next day triplicate samples containing approximately $1.85 \mathrm{kBq}$ of ${ }^{67 / \mathrm{nat}} \mathrm{Ga}-\mathrm{HZ} 220$ $(0.25 \mathrm{pmol})$ were added and the cells incubated at $37^{\circ} \mathrm{C}$ for $0.25,0.5$, 1.0 , and $2.0 \mathrm{~h}$. After $2 \times 5 \mathrm{~min}$ of incubation with glycine buffer $(\mathrm{pH}$ 2.8 ) at $4{ }^{\circ} \mathrm{C}$, the activity remaining on the cells was determined to be internalized fraction. ${ }^{\text {nat }} \mathrm{Ga}$-DOTA-RM2 (1.0 nmol) was used as a blocking agent to determine the nonspecific binding.

To determine the cellular distribution of ${ }^{\text {nat }} \mathrm{Ga}-\mathrm{HZ} 220, \mathrm{PC}-3$ cells $\left(1.0 \times 10^{4}\right.$ per well) were seeded in a 4 -well chamber slide (Nunc Lab-Tek II Chamber Slide System) containing growth medium $(0.5 \mathrm{~mL})$ $1 \mathrm{~d}$ before the experiments. ${ }^{\text {nat }} \mathrm{Ga}-\mathrm{HZ} 220(100 \mathrm{nM})$ was added to incubate with PC-3 cells in the culture medium for $1 \mathrm{~h}$ at $37^{\circ} \mathrm{C}$. For blocking studies, ${ }^{\text {nat }} \mathrm{Ga}$-DOTA-RM2 $(2 \mu \mathrm{M})$ was preincubated with PC-3 cells at $37^{\circ} \mathrm{C}$ for $5 \mathrm{~min}$; then the same amount of ${ }^{\text {nat }} \mathrm{Ga}-\mathrm{HZ} 220(100 \mathrm{nM})$ was added for 1-h incubation at $37^{\circ} \mathrm{C}$. After being washed with medium $(1.0 \mathrm{~mL})$, Hoechst nuclear staining (5 min at room temperature), and phosphatebuffered saline $(3 \times 1.0 \mathrm{~mL})$, the cells were imaged using an inverted confocal microscope (Leica TCS SP8 II).

\section{In Vivo and Ex Vivo Imaging of PC-3 Xenografts}

All animal experiments were approved by the Institutional Animal Care and Use Committee of Memorial Sloan Kettering Cancer Center. Male athymic NCr-nu/nu mice (7-9 wk old; Taconic) were used for subcutaneous implantation. PC- 3 cells $\left(5 \times 10^{6}\right.$ cells suspended in $200 \mu \mathrm{L}$ of cell culture medium/Matrigel [BD Bioscience] $[\mathrm{v} / \mathrm{v}=1 / 1]$ ) were inoculated to the right shoulder of the animal. Twenty to $30 \mathrm{~d}$ after the inoculation, imaging and tissue sampling were performed when the tumor sizes were between 100 and $350 \mathrm{~mm}^{3}$. Starting $3 \mathrm{~d}$ before imaging experiments, mice were fed a diet with low chlorophyll content to reduce intestinal autofluorescence. 
TABLE 1

Analytic and Affinity Data of GRPr Antagonists

\begin{tabular}{lrrrr}
\hline & \multicolumn{2}{c}{ Mass $\left([\mathrm{M}+2 \mathrm{H}]^{+}\right)$} & \\
\cline { 2 - 3 } Compound & Calculated & Measured & & $\mathrm{IC}_{50}(\mathrm{nmol} / \mathrm{L})$ \\
\hline Ga-DOTA-AR & 906.4 & 906.5 & $0.48 \pm 0.18(5)$ \\
Ga-HZ219 & 971.0 & 970.9 & $0.69 \pm 0.18(4)$ \\
Ga-HZ220 & 1430.5 & 1430.4 & $21.4 \pm 7.4(6)$ \\
DOTA-RM2 & 853.4 & 853.7 & $7.7 \pm 3.3$
\end{tabular}

Values (mean $\pm \mathrm{SD}$ ) from binding studies were determined in PC-3 cells. Number of independent experiments is given in parentheses (triplicate measurements were performed in each experiment). Data for DOTA-RM2 are from Mansi et al. (15).

In Vivo Imaging with PET/CT and IVIS Spectrum. Mice bearing PC-3 xenografts were administrated $1.0 \mathrm{nmol}(3.7-11.1 \mathrm{MBq})$ of ${ }^{68} \mathrm{Ga}$-DOTA-RM2 $(n=3),{ }^{68} \mathrm{Ga}$-DOTA-AR $(n=3),{ }^{68} \mathrm{Ga}$-HZ220 $(n=7)$, or ${ }^{68} \mathrm{Ga}-\mathrm{HZ} 220$ plus $150 \mathrm{nmol}{ }^{\text {nat }} \mathrm{Ga}$-DOTA-RM2 for blocking $(n=5)$ via tail vein injection. At $1 \mathrm{~h}$ after injection, PET/CT imaging was performed with an Inveon PET/CT system (Siemens). The imaging protocol is described in the supplemental methods section. Right after PET/CT imaging, animals injected with ${ }^{68} \mathrm{Ga}-\mathrm{HZ} 220$ (4 for nonblocked, 3 blocked) were moved to the IVIS spectrum system for optical imaging. The imaging procedure is described in the supplemental methods section.

Ex Vivo Biodistribution Studies and Imaging. After the imaging procedures described above, the animals were sacrificed for tissue dissection. The organs of interest were collected, rinsed of excess blood, blotted, weighed, and counted with the $\gamma$-counter. The total injected radioactivity per animal was determined from the measured radioactivity in an aliquot of the injectate. Data were expressed as percentage injected activity per gram of tissue (\%IA/g). Excised tumors were frozen and processed for autoradiography, histology, and fluorescence microscopy as described in the supplemental methods section.

\section{Statistical Analysis}

Data calculated using Microsoft Excel are expressed as mean \pm SD. The Student unpaired $t$ test (GraphPad Prism 6) was used to determine statistical significance. Differences with $P$ values of less than 0.05 were considered to be statistically significant.

\section{RESULTS}

Synthesis of Bombesin Antagonists and Their Labeling with ${ }^{68} \mathrm{Ga},{ }^{67} \mathrm{Ga}$, and ${ }^{\text {nat }} \mathrm{Ga}$

HZ219, DOTA-RM2, and DOTA-AR (Fig. 1) were synthesized using an Fmoc strategy affording a maximum yield of approximately $40 \%$ based on the removal of the first Fmoc group; the purity analyzed by UPLC-MS was greater than 95\% (Table 1). HZ220 (Fig. 1) was synthesized by the 1-step reaction between HZ219 and IRDye 650 NHS with a yield of $80 \%$. All ligands, including HZ220, were labeled with ${ }^{68 / 67 / n a t}$ Ga successfully. Their radiolabeling yields were greater than $95 \%$ at specific activities of more than $5.0 \mathrm{GBq} / \mu \mathrm{mol}$ for ${ }^{67} \mathrm{Ga}$ and more than $19.0 \mathrm{GBq} / \mu \mathrm{mol}$ for ${ }^{68} \mathrm{Ga}$ at the end of radiosynthesis.

\section{Binding Affinity Assays}

Table 1 summarizes the binding affinities of ${ }^{n a t} \mathrm{Ga}$ or ${ }^{n a t} / 67 \mathrm{Ga}-$ chelated bombesin antagonists to GRPr on PC-3 cells. With [ ${ }^{125} \mathrm{I}-$ $\mathrm{Tyr}^{4}$ ]bombesin as a radioligand, ${ }^{\text {nat }}$ Ga-labeled DOTA-AR and HZ219 showed a similar subnanomolar affinity on PC-3 cells ( IC $_{50}$ values, $0.48 \pm 0.18$ and $0.69 \pm 0.18 \mathrm{nM}$, respectively). However, when the bulky-functional-group IRDye 650 was introduced into the molecules via conjugation to the $\omega$-amine of lysine, the new molecule,

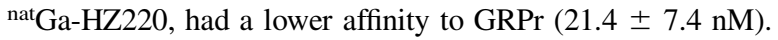

\section{In Vitro Cell Uptake and Fluorescence Microscopy}

The uptake kinetics of ${ }^{67 / n a t} \mathrm{Ga}-\mathrm{HZ} 220$ and its cellular distribution are depicted in Figure 2. ${ }^{67 / n a t} \mathrm{Ga}-\mathrm{HZ} 220$ showed a timedependent accumulation in the cells (Fig. 2A). Approximately half of the radioactivity was bound to the cell surface, whereas the other half was internalized. Uptake was receptor-mediated, because an excess amount of nat Ga-DOTA-RM2 markedly reduced radiotracer uptake (Fig. 2A). Fluorescence microscopy also demonstrated that uptake of ${ }^{67 / n a t} \mathrm{Ga}-\mathrm{HZ} 220$ was blocked by

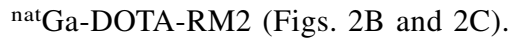

\section{In Vivo and Ex Vivo Imaging of PC-3 Xenografts}

After administration of a single dose of ${ }^{68} \mathrm{Ga}-\mathrm{HZ} 220$, PET/CT and fluorescence images were obtained subsequently in the same
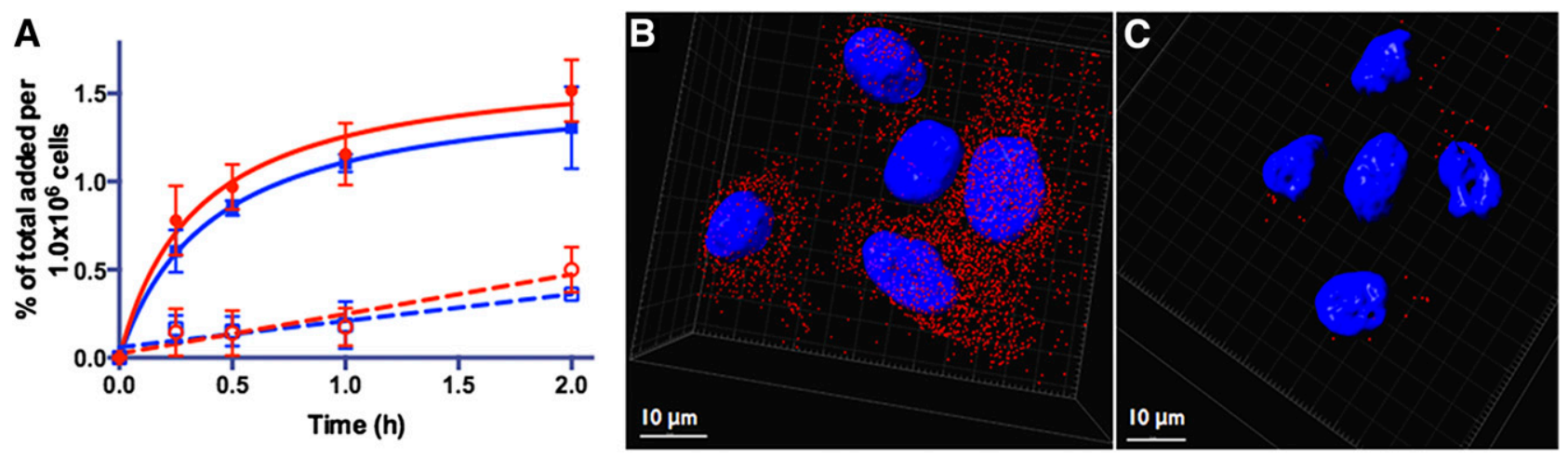

FIGURE 2. In vitro uptake of nat/67Ga-HZ220 in GRPr-expressing PC-3 cells. (A) Uptake kinetics of ${ }^{67} \mathrm{Ga}-\mathrm{HZ220}$ without (solid line) and with blocking dose of $1.0 \mathrm{nmol}$ of Ga-DOTA-RM2 (dashed lines). Internalized fraction (blue) of ${ }^{67} \mathrm{Ga}-\mathrm{HZ} 220$ was slightly lower than bound fraction (red); and both were markedly higher than nonspecific accumulation with blocking dose of Ga-DOTA-RM2. Values (mean \pm SD) were from 2 independent studies with triplicates in each experiment. (B and C) GRPr on PC-3 cells were imaged with inverted confocal microscope together with Ga-HZ220 (B) or Ga-HZ220/Ga-DOTA-RM2 (C). 


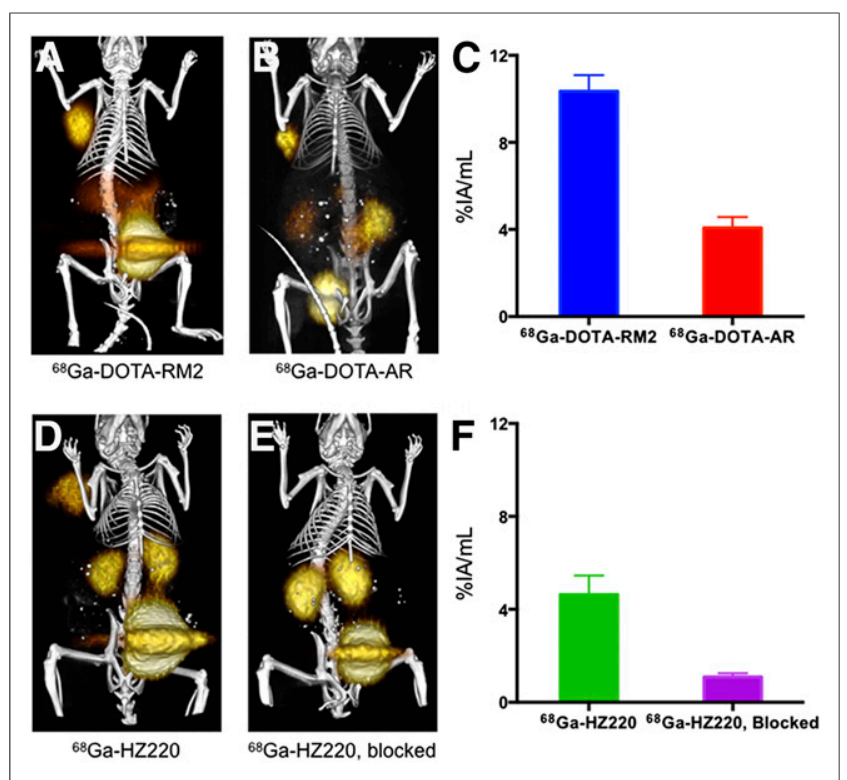

FIGURE 3. In vivo PET/CT imaging of GRPr-expressing PC-3 xenografts with ${ }^{68} \mathrm{Ga}$-labeled bombesin antagonists. PC-3 tumor-bearing mice were imaged at $1 \mathrm{~h}$ after injection with ${ }^{68} \mathrm{Ga}-\mathrm{DOTA}-\mathrm{RM} 2(n=3)$ (A), ${ }^{68} \mathrm{Ga}-\mathrm{DOTA}-\mathrm{AR}(n=3)(\mathrm{B}),{ }^{68} \mathrm{Ga}-\mathrm{HZ} 220(n=7)(\mathrm{D})$, and ${ }^{68} \mathrm{Ga}-$ HZ220, blocked $(n=5)(E)$. Color threshold was optimized to visualize tumor clearly on fusion image. Accurate color-intensity scale bar (\%ID/ $\left.\mathrm{cm}^{3}\right)$ is precluded in these maximum-intensity-projection images (region-of-interest measurements are provided in Figs. 3C and 3F). All 3 radiotracers PET-visualized PC-3 xenografts (solid arrow) with high tumor-to-background contrast, except ${ }^{68} \mathrm{Ga}-\mathrm{HZ} 220$ had a high uptake in kidneys.

animals bearing PC-3 xenografts (Figs. 3 and 4). All ${ }^{68} \mathrm{Ga}$-labeled HZ220, DOTA-RM2, and DOTA-AR clearly delineated PC-3 xenografts from the adjacent background radioactivity in the images (Fig. 3) at $1 \mathrm{~h}$ after injection. Region-of-interest values (\% IA/mL) obtained from the PET images showed that ${ }^{68} \mathrm{Ga}-\mathrm{HZ} 220$ had a slightly higher tumor accumulation than ${ }^{68} \mathrm{Ga}-\mathrm{DOTA}-\mathrm{AR}(4.63 \pm$ 0.31 vs. $4.01 \pm 0.29 \% \mathrm{IA} / \mathrm{mL}, P=0.31)$ but a significantly lower tumor accumulation than ${ }^{68} \mathrm{Ga}-\mathrm{DOTA}-\mathrm{RM} 2(10.4 \pm 0.4 \% \mathrm{IA} / \mathrm{mL}$,

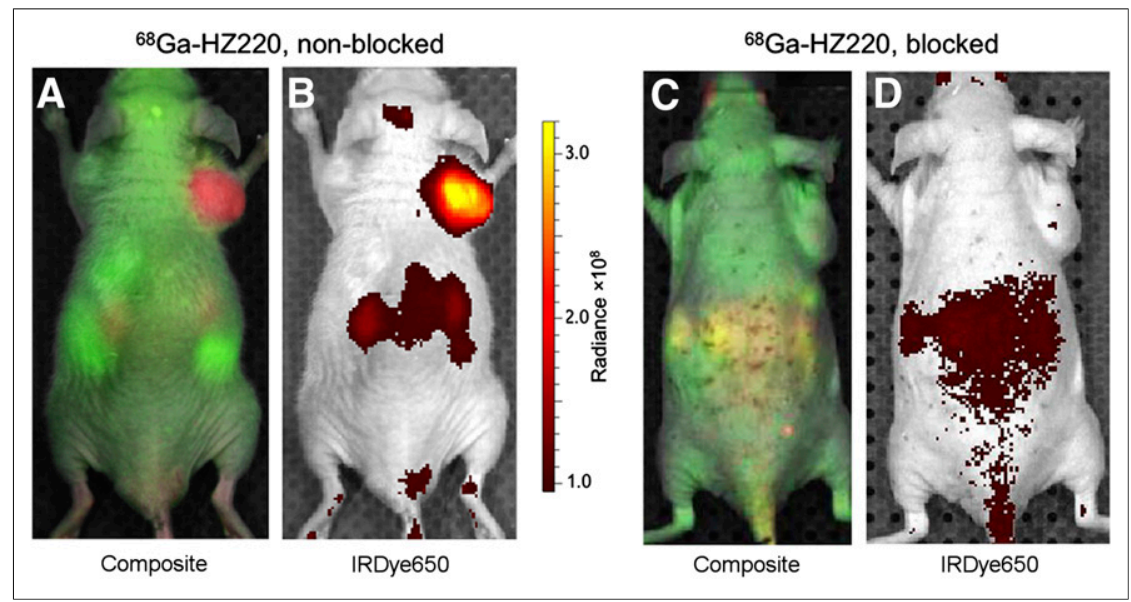

FIGURE 4. In vivo IVIS imaging of GRPr-expressing PC-3 xenografts with ${ }^{68} \mathrm{Ga}-\mathrm{HZ220}$. PC-3 tumor-bearing mice were imaged for $500 \mathrm{~ms}$ at $1 \mathrm{~h}$ after injection of ${ }^{68} \mathrm{Ga}-\mathrm{HZ} 220$ with IVIS spectrum $(n=4)\left(\mathrm{A}\right.$ and B) and ${ }^{68} \mathrm{Ga}-\mathrm{HZ} 220$ plus excess of unlabeled ligand $(n=3, \mathrm{C}$ and $\mathrm{D})$.
$P<0.0001)$. Tumor uptake of ${ }^{68} \mathrm{Ga}-\mathrm{HZ} 220$ was also significantly reduced by an excess of unlabeled ligand $(1.09 \pm 0.09 \% \mathrm{IA} / \mathrm{mL}$, $P<0.0001)$, which indicates that ${ }^{68} \mathrm{Ga}-\mathrm{HZ} 220$ tumor uptake was receptor-mediated. The subsequent biodistribution studies (Table 2) confirmed the observation of PET imaging. Overall, all 3 ligands showed a similar biodistribution, with the exception of a higher kidney uptake of ${ }^{68} \mathrm{Ga}-\mathrm{HZ} 220$ and a higher pancreas uptake of ${ }^{68} \mathrm{Ga}$-DOTA-RM2.

${ }^{68} \mathrm{Ga}-\mathrm{HZ} 220$ fluorescence imaging (Fig. 4) demonstrated a high intensity signal in PC-3 xenografts. Low- ${ }^{68} \mathrm{Ga}-\mathrm{HZ} 220$-derived signals were recorded from the kidneys, probably due to light attenuation (Figs. 4A and 4B). In contrast, there was only background intensity in the blocking study (Figs. 4C and 4D). The subsequent ex vivo image (Fig. 5) confirmed the results from in vivo imaging of PC-3 xenografts with ${ }^{68} \mathrm{Ga}-\mathrm{HZ} 220$. The ${ }^{68} \mathrm{Ga}-\mathrm{HZ} 220$ intensities (unmixed fluorescent image) in PC-3 xenografts were significantly higher than that of the blocked PC-3 xenografts and muscle $\left([6.98 \pm 0.61\right.$ vs. $1.73 \pm 0.93$ vs. $0.27 \pm 0.01] \times 10^{8} \mathrm{p} / \mathrm{s} / \mathrm{cm}^{2} / \mathrm{sr}$ per $\left.\mu \mathrm{W} / \mathrm{cm}^{2}, P<0.005\right)$. The fluorescence intensity from the muscle of blocked animals was slightly higher than that of the nonblocked group $\left([0.57 \pm 0.18] \times 10^{8} \mathrm{p} / \mathrm{s} / \mathrm{cm}^{2} / \mathrm{sr}\right.$ per $\mu \mathrm{W} / \mathrm{cm}^{2}, P=$ 0.1584). Tumor-to-muscle ratios were $25.8 \pm 2.3$ for nonblocked PC-3 xenografts and $1.5 \pm 0.2$ for blocked animals, which is consistent with the higher radioactivity concentration observed in the radioactive-based biodistribution study (Table 2).

The dissected PC-3 xenografts were used for in vitro autoradiography and fluorescence microscopy (Fig. 6). On a macroscopic level the fluorescent signal closely matched the radioactivity detected on the autoradiograms (Fig. 6). Both showed uptake in regions considered as viable by hematoxylin and eosin staining and low uptake in areas of necrosis. However, fluorescent imaging provides considerably higher spatial resolution and allowed visualization of the imaging probe distribution down to the cellular level (Fig. 6, lower row).

\section{DISCUSSION}

Optical molecular imaging has become an attractive modality for intraoperative imaging of cancer resection and has improved the survival rate in cancer patient care (18-20). This study shows for the first time, to our knowledge, that dual-modality, optical and nuclear imaging of GRPr expression is feasible and that ${ }^{68} \mathrm{Ga}-\mathrm{HZ} 220$ is a promising candidate for visualizing prostate cancer with PET and fluorescence cameras. ${ }^{68} \mathrm{Ga}$ HZ220 visualized prostate cancer xenografts with high tumor-to-normal-tissue ratios on PET/CT and also provided highcontrast fluorescence images. Moreover, we could visualize the intratumoral distribution of ${ }^{68} \mathrm{Ga}$-HZ220 after in vivo injection by fluorescence microscopy.

Several fluorescently labeled bombesin agonists have been designed previously and evaluated for targeting GRPr (21-23). However, to our knowledge ${ }^{68} \mathrm{Ga}-\mathrm{HZ} 220$ is the first dual-modality GRPr imaging agent. The advantages of using the same imaging probe for both PET and optical imaging are many-fold. First, the regulator process for clinical translation is simplified because 
TABLE 2

Biodistribution of ${ }^{68} \mathrm{Ga}$-Labeled HZ220, DOTA-AR, and DOTA-RM2 in PC-3 Xenografts After PET Imaging

\begin{tabular}{|c|c|c|c|c|}
\hline \multirow[b]{2}{*}{ Organ } & \multicolumn{2}{|c|}{${ }^{68} \mathrm{Ga}-\mathrm{HZ} 220$} & \multirow[b]{2}{*}{${ }^{68} \mathrm{Ga}-\mathrm{DOTA}-\mathrm{RM} 2,1 \mathrm{~h}(n=3)$} & \multirow[b]{2}{*}{${ }^{68} \mathrm{Ga}-\mathrm{DOTA}-\mathrm{AR}, 1 \mathrm{~h}(n=3$} \\
\hline & $1 \mathrm{~h}(n=7)$ & $1 \mathrm{~h}$, blocked $(n=5)$ & & \\
\hline PC-3 & $5.50 \pm 1.03$ & $1.20 \pm 0.30$ & $9.14 \pm 0.49$ & $4.53 \pm 1.11$ \\
\hline Blood & $0.78 \pm 0.62$ & $0.93 \pm 0.31$ & $0.20 \pm 0.03$ & $0.24 \pm 0.06$ \\
\hline Muscle & $0.15 \pm 0.06$ & $0.25 \pm 0.14$ & $0.05 \pm 0.01$ & $0.19 \pm 0.24$ \\
\hline Heart & $0.28 \pm 0.10$ & $0.43 \pm 0.17$ & $0.09 \pm 0.01$ & $0.11 \pm 0.01$ \\
\hline Lung & $1.93 \pm 1.56$ & $1.85 \pm 0.51$ & $0.19 \pm 0.08$ & $0.61 \pm 0.21$ \\
\hline Liver & $1.03 \pm 0.42$ & $1.35 \pm 0.46$ & $0.27 \pm 0.02$ & $0.81 \pm 0.16$ \\
\hline Pancreas & $2.70 \pm 1.51$ & $0.69 \pm 0.22$ & $8.67 \pm 3.01$ & $3.76 \pm 0.66$ \\
\hline Spleen & $0.49 \pm 0.46$ & $0.46 \pm 0.14$ & $0.45 \pm 0.26$ & $0.19 \pm 0.05$ \\
\hline Stomach & $0.46 \pm 0.22$ & $0.44 \pm 0.18$ & $1.01 \pm 0.07$ & $0.61 \pm 0.15$ \\
\hline Small intestine & $0.50 \pm 0.28$ & $0.48 \pm 0.21$ & $0.87 \pm 0.23$ & $0.89 \pm 0.65$ \\
\hline Large intestine & $0.29 \pm 0.08$ & $0.29 \pm 0.13$ & $0.81 \pm 0.09$ & $0.35 \pm 0.07$ \\
\hline Bone & $0.34 \pm 0.24$ & $0.35 \pm 0.15$ & $0.12 \pm 0.03$ & $0.23 \pm 0.19$ \\
\hline Kidney & $16.9 \pm 6.5$ & $20.1 \pm 6.1$ & $5.01 \pm 2.29$ & $4.58 \pm 1.63$ \\
\hline Brain & $0.03 \pm 0.01$ & $0.04 \pm 0.01$ & $0.03 \pm 0.01$ & $0.03 \pm 0.02$ \\
\hline \multicolumn{5}{|l|}{ Tumor-to-organ ratios } \\
\hline PC-3 to blood & $9.0 \pm 2.9$ & $1.4 \pm 0.6$ & $33 \pm 22$ & $20 \pm 10$ \\
\hline PC-3 to muscle & $40 \pm 11$ & $6.4 \pm 4.4$ & $211 \pm 47$ & $103 \pm 63$ \\
\hline PC-3 to pancreas & $3.0 \pm 2.7$ & $1.9 \pm 0.8$ & $1.2 \pm 0.5$ & $1.2 \pm 0.3$ \\
\hline PC-3 to kidney & $0.4 \pm 0.1$ & $0.1 \pm 0.0$ & $2.1 \pm 0.8$ & $1.1 \pm 0.5$ \\
\hline
\end{tabular}

only 1 investigational agent is studied. Furthermore, the radioactivity distribution in the preoperative PET imaging is identical to the intraoperative distribution of the optical probe. With 2 different

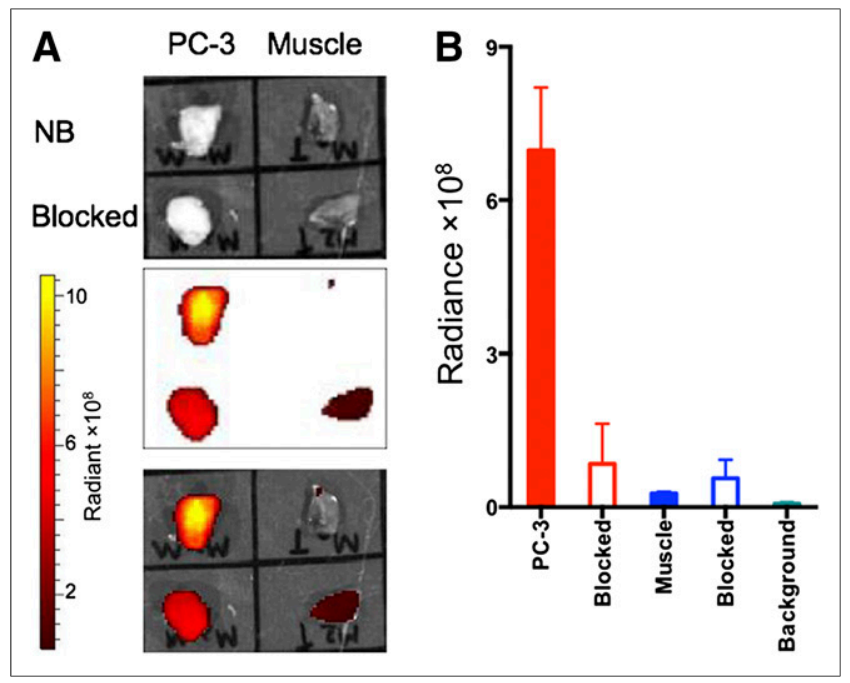

FIGURE 5. Ex vivo fluorescence imaging of GRPr-expressing PC-3 xenografts with ${ }^{68} \mathrm{Ga}-\mathrm{HZ} 220$. (A) White light images (top), fluorescence imaging (middle), and fused white light/fluorescence images (bottom) of tissue samples taken from mice who did (blocked) or did not (NB) receive blocking dose of natGa-DOTA-RM2. (B) Quantitative analysis of corresponding fluorescence images of tissue samples $(n=4$ for nonblocked group; $n=3$ for blocked group). Intensity of fluorescence signal was expressed as average radiant efficiency of $\mathrm{p} / \mathrm{s} / \mathrm{cm}^{2} / \mathrm{sr}$ (number of photons [p] per second [s] per surface area [ $\left.\mathrm{cm}^{2}\right]$ per steradian [sr]) per $\mu \mathrm{W} / \mathrm{cm}^{2}$. imaging agents, tumor uptake and image contrast may be different, limiting the ability of PET imaging to select patients who are likely to benefit from intraoperative imaging with a GRPr-targeted optical imaging agent. Scientifically, perhaps the most important advantage is, however, that after surgery the distribution of the imaging probe in the resected specimen can be studied immediately by fluorescence microscopy (Fig. 6). Because the optical and the nuclear imaging probes are identical, it is possible to discriminate between those cells that accumulate the PET imaging probes and those that do not. This is of great interest in prostate cancer, which is frequently multifocal and coexists with benign changes in the prostate (i.e., prostatitis and benign prostate hyperplasia). Because benign and malignant changes frequently occur in close spatial proximity, it can be challenging to ensure that uptake of an imaging agent is due to prostate cancer and not due to a neighboring benign finding. Prostate tissue shrinks during fixation for histology, and the spheric shape of the prostates makes coregistering the imaging findings and histologic sections challenging, because internal landmarks to assess the quality of the coregistration process are lacking. Thus, being able to visualize the distribution of an imaging agent with high spatial resolution with fluorescence microcopy is extremely valuable to validate its accuracy for prostate cancer imaging.

To radiolabel HZ220 with ${ }^{68} \mathrm{Ga}$, we had to modify the routine conditions for labeling DOTA with radiogallium. We observed that at a $\mathrm{pH}$ of 4 or less the fluorescence of IRDye 650 was lost within seconds, even at room temperature. Azhdarinia et al. (3) reported that the labeling condition for ${ }^{68} \mathrm{Ga},{ }^{111} \mathrm{In},{ }^{64} \mathrm{Cu}$, and ${ }^{99 \mathrm{~m}} \mathrm{Tc}$ resulted in a decreased brightness of different NIRF dyes. The low $\mathrm{pH}$ of a ${ }^{99 \mathrm{~m}} \mathrm{Tc}$ solution caused a loss of fluorescent properties of indocyanine green (24). When the $\mathrm{pH}$ was between 


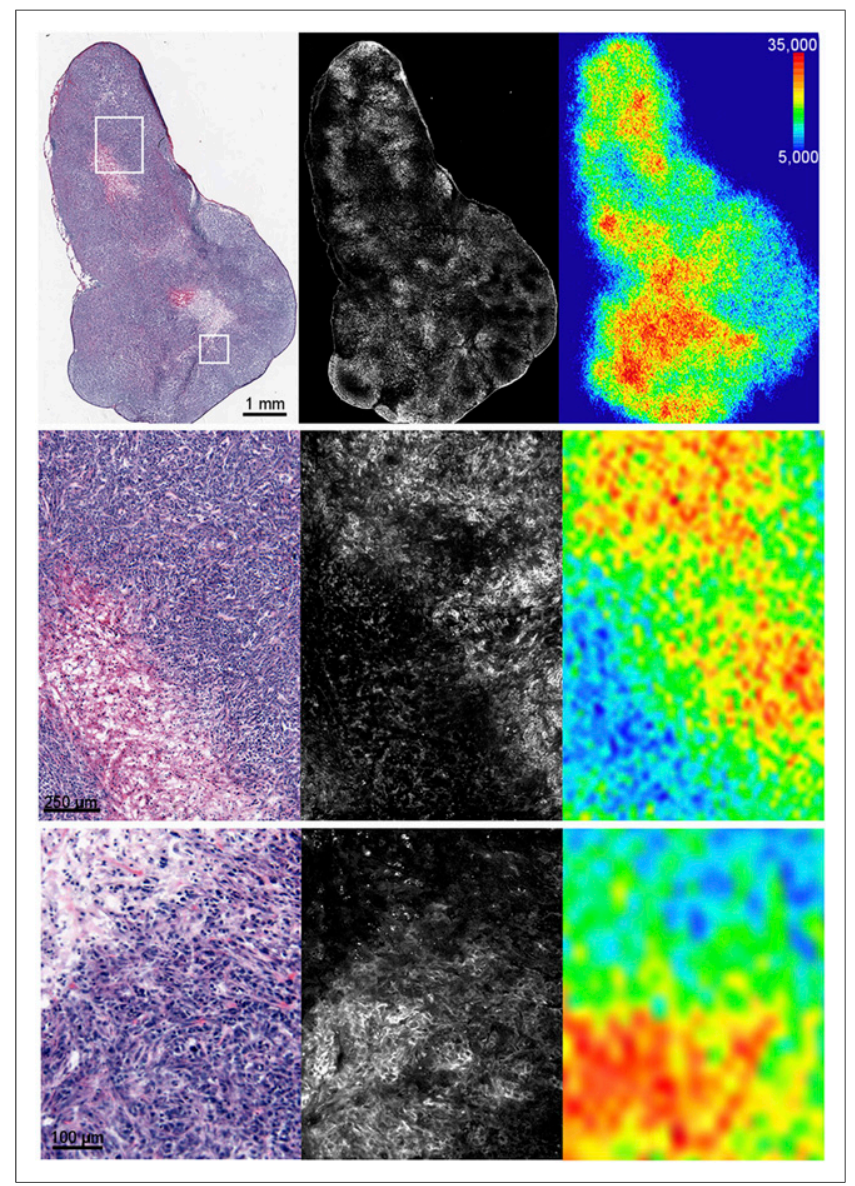

FIGURE 6. Ex vivo hematoxylin and eosin staining (left), fluorescence microscopy (middle), and autoradiography (right) of PC-3 xenografts after administration of ${ }^{68} \mathrm{Ga}-\mathrm{HZ} 220$. The 3 rows show 3 levels of magnification as indicated by black scale bar.

5 and 5.5, the fluorescence of HZ220 remained intact during ${ }^{68} \mathrm{Ga}$ complexation. Under these optimized conditions, ${ }^{68} \mathrm{Ga}-\mathrm{HZ} 220$ was prepared successfully, with a radiochemical purity of greater than $95 \%$, and its specific activities were greater than $19.0 \mathrm{GBq} / \mu$ mole at the end of radiosynthesis. When $740 \mathrm{MBq}$ of eluted ${ }^{68} \mathrm{Ga}(\mathrm{OH})_{4}{ }^{-}$in $0.5 \mathrm{~mL}$ of $\mathrm{KOH}$ were used for radiolabeling, we obtained $477 \mathrm{MBq}$ of ${ }^{68} \mathrm{Ga}-\mathrm{HZ} 220$ (highest dose) in our radiosynthesis, which would therefore be sufficient for 2 patient studies (assuming 144-185 MBq per patient).

During ${ }^{68} \mathrm{Ga}$ labeling of peptides, only a small fraction of the total peptide is actually radiolabeled $(\sim 1 \%)$. The radiolabeled and the nonradiolabeled peptide do not necessarily show the same target binding affinity. As a consequence, tumor uptake and biodistribution of the radiolabeled and the nonradiolabeled peptide may be different. Therefore, it is important that our biodistribution studies and autoradiographic images demonstrate that HZ220 and ${ }^{68} \mathrm{Ga}$ show the same biodistribution on a macroscopic and microscopic level.

Ga-HZ220 competitively inhibited binding of the GRPr agonist $\left[{ }^{125} \mathrm{I}_{-\mathrm{Tyr}^{4}}\right]$ bombesin to PC-3 cells $\left(\mathrm{IC}_{50}=21.4 \pm 7.4 \mathrm{nM}\right)$. This indicates a lower affinity than that of non-fluorescent-conjugated ligands (Table 1), including ${ }^{\text {nat }}$ Ga-DOTA-RM2 (BAY 86-7548), which has been used for clinical trials $(11,25)$. Thus, the relatively bulky IRDye 650 interfered to some extent with the binding of the peptide to GRPr. It is known that the spacer between the affinity sequence and radiometal chelator can improve binding profile and change biodistribution of radiolabeled GRPr ligands (26). A similar phenomenon was also observed when a fluorescent dye was conjugated at the $\mathrm{N}$ terminus of the affinity peptide (21). Thus, modification of HZ220 with different spacers may improve affinity. Recently, other novel strategies have been introduced to construct dual-modality scaffolds $(12,13)$; it will also be interesting to investigate how these scaffolds influence the ligand affinity and in vivo pharmacologic behavior.

In cell culture, approximately $50 \%$ of the total cell-bound ${ }^{67} \mathrm{Ga}-$ HZ220 was internalized in a receptor-dependent manner. This is different from DOTA-RM2, which has shown only a low internalization rate (15). Thus, integration of IRDye 650 at the $\mathrm{N}$ terminus appears to improve internalization of receptor-bound ${ }^{68} \mathrm{Ga}-\mathrm{HZ} 220$, but future studies are necessary to understand the mechanisms for this observation.

In vivo radiotracer uptake of ${ }^{68} \mathrm{Ga}-\mathrm{HZ} 220$ in PC-3 xenografts and pancreas (GRPr-positive) was similar to the structurally similar ${ }^{68} \mathrm{Ga}$-DOTA-AR, despite the fact that ${ }^{68} \mathrm{Ga}$-DOTA-AR has a markedly higher affinity for GRPr (Tables 1 and 2). However, uptake of ${ }^{68} \mathrm{Ga}-\mathrm{H} 220$ was lower than that of ${ }^{68} \mathrm{Ga}-$ DOTA-RM2, which has a lower affinity than ${ }^{68} \mathrm{Ga}$-DOTA-AR but a higher affinity than ${ }^{68} \mathrm{Ga}-\mathrm{HZ} 220$. This result emphasizes that receptor affinity is only 1 factor determining tumor uptake of GRPr ligands as has been shown in prior studies (27). It is also interesting to find out that the integration of IRDye 650 might not influence the tumor accumulation but increased the retention of ${ }^{67 / 68} \mathrm{Ga}-\mathrm{HZ} 220$ in kidney and blood. The reasons for the enhanced kidney uptake are not obvious and are still being investigated. However, the reduced affinity of HZ220 for GRPr might have reduced the accumulation in the intestine and pancreas, leading to a higher tumor-to-tissue ratio (contrast) when compared with ${ }^{68} \mathrm{Ga}$-DOTA-RM2, which is actually an improvement in terms of PET imaging contrast. The tumor-to-muscle ratio of ${ }^{68} \mathrm{Ga}-\mathrm{HZ} 220$ from the calculation of fluorescent signals was $25.8 \pm 2.3$, which was higher than other fluorescent-conjugated bombesin agonists (22).

\section{CONCLUSION}

We designed and biologically characterized ${ }^{68} \mathrm{Ga}-\mathrm{HZ220}$, the first bimodal ligand for PET imaging of GRPr expression. The high image contrast achieved with ${ }^{68} \mathrm{Ga}-\mathrm{HZ} 220$ for both PET and optical imaging is promising for the clinical translation of GRPr-targeting bimodal imaging agents for prostate cancer imaging.

\section{DISCLOSURE}

This study was supported by NIH P50-CA84638. Technical services from the MSK Core Facilities were supported by NIH Cancer Center support grant P30 CA08748. Hanwen Zhang was additionally supported by CURE Childhood Cancer Foundation. No other potential conflict of interest relevant to this article was reported.

\section{ACKNOWLEDGMENTS}

We gratefully acknowledge the staff of the MSK Small Animal Imaging Core Facility and the use of the ${ }^{68} \mathrm{Ge} /{ }^{68} \mathrm{Ga}$ generator from ANSTO, Australia. 


\section{REFERENCES}

1. Yossepowitch O, Bjartell A, Eastham JA, et al. Positive surgical margins in radical prostatectomy: outlining the problem and its long-term consequences. Eur Urol. 2009;55:87-99.

2. Fesseha T, Sakr W, Grignon D, Banerjee M, Wood DP Jr, Pontes JE. Prognostic implications of a positive apical margin in radical prostatectomy specimens. $J$ Urol. 1997;158:2176-2179.

3. Azhdarinia A, Ghosh P, Ghosh S, Wilganowski N, Sevick-Muraca EM. Duallabeling strategies for nuclear and fluorescence molecular imaging: a review and analysis. Mol Imaging Biol. 2012;14(3):261-276.

4. Nguyen QT, Tsien RY. Fluorescence-guided surgery with live molecular navigation: a new cutting edge. Nat Rev Cancer. 2013;13:653-662.

5. Lütje S, Rijpkema M, Helfrich W, Oyen WJ, Boerman OC. Targeted radionuclide and fluorescence dual-modality imaging of cancer: preclinical advances and clinical translation. Mol Imaging Biol. 2014;16(6):747-755.

6. Reubi JC, Wenger S, Schmuckli-Maurer J, Schaer JC, Gugger M. Bombesin receptor subtypes in human cancers: detection with the universal radioligand ${ }^{125} \mathrm{I}_{-}\left[\mathrm{D}-\mathrm{TYR}_{6}\right.$, beta-ALA $\left.11, \mathrm{PHE}_{13}, \mathrm{NLE}_{14}\right]$ bombesin(6-14). Clin Cancer Res. 2002;8:1139-1146.

7. Markwalder R, Reubi JC. Gastrin-releasing peptide receptors in the human prostate: relation to neoplastic transformation. Cancer Res. 1999;59:1152-1159.

8. Mansi R, Fleischmann A, Macke HR, Reubi JC. Targeting GRPR in urological cancers-from basic research to clinical application. Nat Rev Urol. 2013;10:235-244.

9. Mather SJ, Nock BA, Maina T, et al. GRP receptor imaging of prostate cancer using [99m Tc]demobesin 4: a first-in-man study. Mol Imaging Biol. 2014;16(6):888-895.

10. Liu Y, Hu X, Liu H, et al. A comparative study of radiolabeled bombesin analogs for the PET imaging of prostate cancer. J Nucl Med. 2013;54:2132-2138.

11. Kähkönen E, Jambor I, Kemppainen J, et al. In vivo imaging of prostate cancer using [ $\left.{ }^{68} \mathrm{Ga}\right]-$ labeled bombesin analog BAY86-7548. Clin Cancer Res. 2013;19: 5434-5443.

12. Sun Y, Ma X, Cheng K, et al. Strained cyclooctyne as a molecular platform for construction of multimodal imaging probes. Angew Chem Int Ed Engl. 2015;54: 5981-5984.

13. Sun L, Ding J, Xing W, Gai Y, Sheng J, Zeng D. A novel strategy for preparing dual-modality optical/PET imaging probes via the photo-click chemistry. Bioconjug Chem. 2016;27:1200-1204.

14. Louie A. Multimodality imaging probes: design and challenges. Chem Rev. 2010;110:3146-3195.
15. Mansi R, Wang X, Forrer F, et al. Development of a potent DOTA-conjugated bombesin antagonist for targeting GRPr-positive tumours. Eur J Nucl Med Mol Imaging. 2011;38:97-107.

16. Zhang H, Abiraj K, Thorek DL, et al. Evolution of bombesin conjugates for targeted PET imaging of tumors. PLoS One. 2012;7:e44046.

17. Zhang H, Huang R, Cheung NK, et al. Imaging the norepinephrine transporter in neuroblastoma: a comparison of $\left[{ }^{18} \mathrm{~F}\right]-\mathrm{MFBG}$ and ${ }^{123} \mathrm{I}-\mathrm{MIBG}$. Clin Cancer Res. 2014;20:2182-2191.

18. Chi C, Du Y, Ye J, et al. Intraoperative imaging-guided cancer surgery: from current fluorescence molecular imaging methods to future multi-modality imaging technology. Theranostics. 2014;4:1072-1084.

19. Wyld L, Audisio RA, Poston GJ. The evolution of cancer surgery and future perspectives. Nat Rev Clin Oncol. 2015;12:115-124.

20. Keating JJ, Okusanya OT, De Jesus E, et al. Intraoperative molecular imaging of lung adenocarcinoma can identify residual tumor cells at the surgical margins. Mol Imaging Biol. 2016;18:209-218.

21. Shrivastava A, Ding H, Kothandaraman S, et al. A high-affinity near-infrared fluorescent probe to target bombesin receptors. Mol Imaging Biol. 2014;16:661669.

22. Cai QY, Yu P, Besch-Williford C, et al. Near-infrared fluorescence imaging of gastrin releasing peptide receptor targeting in prostate cancer lymph node metastases. Prostate. 2013;73:842-854.

23. Levi J, Sathirachinda A, Gambhir SS. A high-affinity, high-stability photoacoustic agent for imaging gastrin-releasing peptide receptor in prostate cancer. Clin Cancer Res. 2014;20:3721-3729.

24. Sevick-Muraca EM, Sharma R, Rasmussen JC, et al. Imaging of lymph flow in breast cancer patients after microdose administration of a near-infrared fluorophore: feasibility study. Radiology. 2008;246:734-741.

25. Roivainen A, Kahkonen E, Luoto P, et al. Plasma pharmacokinetics, whole-body distribution, metabolism, and radiation dosimetry of ${ }^{68} \mathrm{Ga}$ bombesin antagonist BAY 86-7548 in healthy men. J Nucl Med. 2013;54:867-872.

26. Zhang H. Design, synthesis, and preclinical evaluation of radiolabeled bombesin analogues for the diagnosis and targeted radiotherapy of bombesin-receptor expressing tumors. University of Basel edoc website. http://edoc.unibas.ch/586/1/ DissB_7877.pdf. 2006. Accesses September 9, 2016.

27. Mansi R, Abiraj K, Wang X, et al. Evaluation of three different families of bombesin receptor radioantagonists for targeted imaging and therapy of gastrin releasing peptide receptor (GRP-R) positive tumors. J Med Chem. 2015;58: $682-691$. 